according to Kerr index ( $>2$ ), and had also evidence of active disease at PET/CT. Table 1 summarizes the main results of our study.

Despite RTX treatment, 4 of the 7 patients had evidence of persistent disease activity and/or radiographic disease progression during follow-up.

Three out of 7 patients in whom RTX was employed as rescue therapy achieved complete remission.

Conclusions: Our data do not support a role for RTX as first line biologic therapy in TAK patients, but it may have a role in some patients as second/third line biological therapy.

References:

[1] Hoyer BF et al. Takayasu arteritis is characterised by disturbances of B cell homeostasis and responds to B cell depletion therapy with rituximab. Ann Rheum Dis 2012;71:75-9. doi:10.1136/ard.2011.153007.

Disclosure of Interest: None declared

DOI: 10.1136/annrheumdis-2017-eular.5158

\section{AB0564 TEMPORAL ARTERITIS: IS THERE ANY CORRELATION BETWEEN ULTRASONOGRAPHIC ARTERIAL WALL INVOLVEMENT AND THE INFLAMMATORY CELLULAR INFILTRATE AT HISTOLOGICAL EXAMINATION?}

G. Germano ${ }^{1}$, P.L. Macchioni ${ }^{1}$, A. Cavazza ${ }^{2}$, L. Cimino $^{3}$, F. Muratore ${ }^{1}$, C. Salvarani ${ }^{1} .{ }^{1}$ Rheumatology Unit; ${ }^{2}$ Pathology Unit; ${ }^{3}$ Ophthalmology Unit, IRCCS Arcispedale Reggio Emilia, Reggio Emilia, Italy

Background: Ultrasonographic alterations such as the halo sign and the compression test are now accepted as surrogate markers of artery inflammation. No data have yet been published on the correlation between the ultrasonographic grading of arterial wall inflammation and the grading of cellular infiltrate.

Objectives: To compare a semiquantitative ultrasonographic grading (USG) of TA involvement (halo sign and media-intima thickness) with a semiquantitative grading of the inflammatory burden in patients with giant cell (temporal) arteritis (GCA).

Methods: Fiftheen consecutive patients with new onset clinical symptoms and satisfiing ACR criteria for GCA, with positive halo sign in the frontal branch and positive temporal artery biopsy have been enrolled. For each patients we performed power Doppler ultrasonography of temporal artery with a $18-6 \mathrm{MHz}$ linear probe (Esaote MyLab 70) and measured the maximum halo thickness of TA frontal branch in a quantitative and semiquantitave (0-3) grade of involvement $(0=<0.37 \mathrm{~mm}, 1=$ in between $0.38-0.44,2=0.45-0.6 \mathrm{~mm}, 3=>0.6)$. TA biopsy was done in the same frontal branch evalutaed with US. Then we compared the ultrasonographic data with a semiquantitative (0: absent, 1: mild, 2: moderate, 3: severe) grading of the trasmural cellular inflammatory infiltrate and with the intima-media thickness of the TA biopsy specimen. Moreover US results were correlated with the other patterns of histological alterations (giant cells, calcifications, laminar necrosis). Correlation between variables was done by Rho of Spearman method.

Ultrasonography of temporal artery: grading of Halo thickness

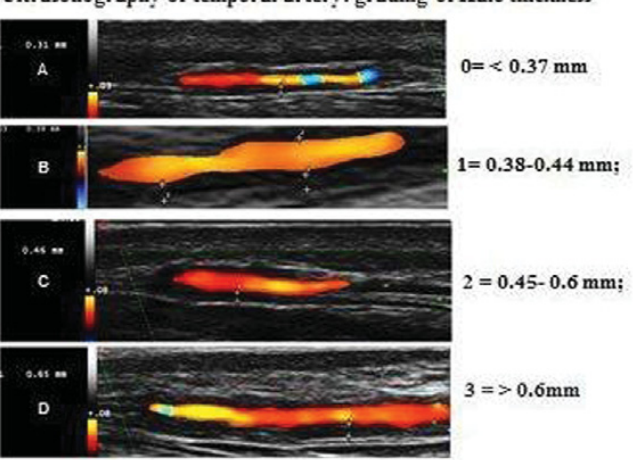

Grading of the trasmural cellular inflammatory infiltrate and intimamedia thickness of the TA biopsy.

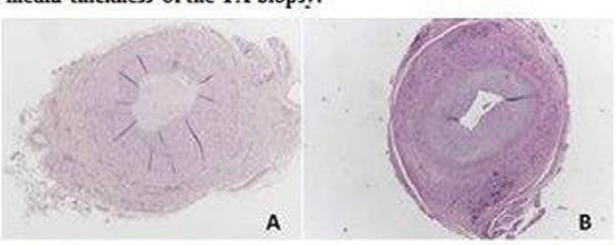

A) Mild inflammation with mild intimal hyperplasia;

B) Moderate inflammation with moderate intimal hyperplasia;

C) Severe inflammation with severe intimal hyperplasia;
Results: 15 patients, 6 males and 9 females (mean age $71.6 \pm 7$ years - duration symptoms at onset $1.7 \pm 1.3$ months - mean ESR $60 \mathrm{~mm} / \mathrm{h} \pm 29-$ mean CRP 8 $\mathrm{mg} / \mathrm{dl} \pm 5.2)$ entered the study. US halo sign was bilateral in $10 / 15(66,7 \%)$. The mean halo thickness was $0.53 \mathrm{~mm} \pm 0.12$. Five patients had $U S G=1$, six patients $=2$ and four patients $=3$. The hystological inflammatory grade 1 was present in seven pts, grade 2 in four and grade 3 in four pts. No significant correlation were found between USG and histological inflammatory grade, nor with the presence of giant cells, calcifications, laminar necrosis and intima-media thickness.

Conclusions: No correlation has been found between the size of the halo sign and the hystological inflammatory grading.

Disclosure of Interest: None declared

DOI: 10.1136/annrheumdis-2017-eular.5093

\section{AB0565 INSUFFICIENT INFLUENZA VACCINATION COVERAGE IN GIANT CELL ARTERITIS. A FRENCH POPULATION-BASED STUDY}

G. Pugnet ${ }^{1}$, M. Lapeyre-Mestre ${ }^{2}$, M. Mounie ${ }^{2}$, G. Moulis ${ }^{1}$, L. Sailler ${ }^{1}$. ${ }^{1}$ Service de Médecine Interne, CHU Toulouse Purpan; ${ }^{2}$ INSERM UMR 1027, Toulouse, France

Background: French general health insurance scheme has implemented a national influenza vaccination program, including full refund for those 65 years old or more. Despite this program, only 62.6 to $71 \%$ of people aged over 65 years are vaccinated and no data are available regarding influenza vaccination coverage (IVC) in GCA.

Objectives: To evaluate the rate and the factors associated with seasonal influenza vaccination coverage in incident giant cell arteritis (GCA) patients compared with controls.

Methods: Using the French National Health Insurance system (SNIIRAM), we included patients with incident GCA from the Midi-Pyrenees region, southern France, and randomly selected 6 controls matched by sex and age at calendar date from January 2005 to December 2008 and followed them till April 2011. The vaccination rate was estimated from vaccine dispensation registered in the SNIIRAM. IVC was compared between GCA and their controls using longitudinal multivariate Poisson regression.

Results: Eighty-seven incident GCA patients over 65 years of age and 509 in the control group were included. Mean follow-up was $4.4 \pm 1.2$ and $4.2 \pm 1.2$ years, respectively. During the yearly influenza campaigns from 2005-2006 to 2010-2011, the IVC rates in the GCA group and the control group ranged from 60.8 to $74.7 \%$ vs 56.6 to $70.4 \%$, respectively. Incident GCA influenza vaccination rate was $20 \%$ higher than controls $(R R=1.20$; IC 1.09 to $1.32, P<0.001)$ (Table 1).

Table 1. Associated factors with recommended influenza vaccination (Multivariate longitudinal Poisson analysis)

\begin{tabular}{|c|c|c|c|c|}
\hline & & Adjusted RR & IC 95\% & $\mathbf{P}$ \\
\hline$\overline{G C A}$ & GCA & 1.20 & $1.09-1.32$ & $<0.001$ \\
\hline \multicolumn{5}{|l|}{ Comorbidity at baseline } \\
\hline - High blood pressure & & 1.13 & $1.04-1.24$ & 0.006 \\
\hline \multirow[t]{3}{*}{ Age, years } & $164.4 ; 71.5]$ & 1 & & \\
\hline & $171.5 ; 80]$ & 1.15 & $1-1.32$ & 0.048 \\
\hline & $180 ; 91.9]$ & 1.13 & $0.99-1.29$ & 0.079 \\
\hline Gender & Female & 1.05 & $0.96-1.16$ & 0.259 \\
\hline \multirow[t]{3}{*}{ Time, Influenza camoaigns. } & [2005: 2008] & 1 & & \\
\hline & [2008: 2010] & 1.11 & $1.08-1.14$ & $<0.001$ \\
\hline & [2010 : 2011] & 1.05 & $1.02-1.08$ & 0.002 \\
\hline \multirow[t]{2}{*}{ GCA"Time } & GCA * [2008: 2010] & 0.90 & $0.87-0.92$ & $<0.001$ \\
\hline & $\mathrm{GCA}^{*}[2010: 2011]$ & 0.77 & $0.72-0.83$ & $<0.001$ \\
\hline
\end{tabular}

Conclusions: Rates of recommended influenza vaccinations are insufficient in GCA patients over 65 years. More attention should be paid for appropriate vaccination during GCA course.

Disclosure of Interest: None declared

DOI: 10.1136/annrheumdis-2017-eular.1814

\section{AB0566 18F-FDG-PET-POSITIVE TEMPORAL ARTERY IN GIANT CELL ARTERITIS: A POSSIBLE CORRELATION WITH HISTOPATHOLOGICAL FINDINGS}

H. Kono ${ }^{1}$, Y. Okada ${ }^{1}$, K. Asako ${ }^{1}$, H. Kikuchi ${ }^{1}$, Y. Oguchi ${ }^{1}$, Z.-I. Honda ${ }^{1}$

A. Takeuchi ${ }^{1}$, T. Tokairin ${ }^{2}$, K. Saito ${ }^{2} .{ }^{1}$ Department of Internal Medicine;

${ }^{2}$ Department of Pathology, Teikyo University School of Medicine, Tokyo, Japan

Background: Giant cell arteritis (GCA) a form of vasculitis in persons older than 50 years, in which cranial and systemic large vessels can be involved. ${ }^{18} \mathrm{~F}$-fluorodeoxyglucose positron emission tomography - computed tomography $\left({ }^{18} \mathrm{~F}\right.$-FDG-PET-CT) is increasingly used to diagnose inflammation of the large arteries in GCA. But it is very rare to observe an inflammation of temporal arteries of GCA using ${ }^{18}$ F-FDG-PET. 